Article

\title{
Smart Techniques in Urban Planning: An Insight to Ruled-Based Design
}

\author{
Carlo Pisano ${ }^{1, *}$, Giuseppe De Luca ${ }^{1}(\mathbb{D})$ and Ahmadreza Shirvani Dastgerdi ${ }^{2}$ (i) \\ 1 Department of Architecture, University of Florence, 50100 Florence, Italy; iuseppe.deluca@unifi.it \\ 2 School of Architecture and Design, University of Camerino, 63100 Ascoli Piceno, Italy; \\ ahmadreza.shirvani@unicam.it \\ * Correspondence: carlo.pisano@unifi.it
}

Received: 8 November 2019; Accepted: 19 December 2019; Published: 22 December 2019

\begin{abstract}
In the last decades, the ideology of managing the city form and performance through pre-determined plans has gradually lost its validity. Some contemporary urban planning theories suggest the application of smart design techniques for managing urban complexity. However, the proposed approach has partially been experienced in practice, and more research on how to integrate them into urban planning is needed. This study aims to present an insight into the rule-based design as a smart design technique for a shift from pre-determined urban plans to design rules. The methodology is based on a comparative analysis between the experiments of some cases in the north of Europe. Research findings highlight that the capacity to deliver variety with harmony, the distinction between the roles of code writer and building designer, the potential to support the implementation process and to prescribe specific qualities, both for the spatial and organizational purposes, are significant factors for the integration of smart design techniques to urban planning.
\end{abstract}

Keywords: urban planning; urban complexity; smart design techniques; rule-based design

\section{Introduction}

In the last decades, due to the growth and strengthening of different topics in urban planning, contemporary urbanism has been slowly veering away from the idea of managing the city form and performances through pre-determined models like master plans, standards, and grand schemes. This idea began with Ilya Prigogine's theory of Dissipative Structures [1], which opened the so-called era of complexity and uncertainty [2], and has developed through urban theories and practices that have been characterized by the notion of complexity, related to the adaptation of numerous system components that generate unpredictable pattern behaviors on the large scale [3-5]. However, designers are less trained to cope with urban rules, intended as abstract patterns that define physical relationships that are lying behind the urban form, which are usually left to municipal building authorities, their administrators, lawyers, and economists [6]. Although rules have been often conceived as potential constraints over artistic creativity, it could easily be claimed that they have always been underlying any composition and control of urban form. As explained by Carmona et al. [7], different forms of regulation of the built environment have occurred throughout recorded history [8]. For instance, the use of codes can be traced back as far as Roman times [9]; this can be seen in Roman street standards [10], or through reference to Vitruvius [11], whose Ten Books on Architecture covered such issues as the layout of cities-including choice of a healthful site, construction of city walls, orientation, and public spaces-public and private buildings, and use of building materials [12].

Many aspects-such as attention to ecology as a practical framework, the smart-cityness connected to the ever-present information and communication technologies and devices, the growing awareness around the issue of social interaction and self-governance-strongly questioned and undermined the 
deterministic models as tools to predict the future form of cities [13]. The recognition of the limits of the conventional approaches towards the theme of urban complexity ends up with a new generation of urban studies aiming with insight rather than prediction [14]. Therefore, this led to an updated outlook of urbanism based on bottom-up collective pattern formation and control rather than the single-minded pursuit of pre-determined models [13].

Under these conditions, several new forms of hybrid and flexible urban approaches have emerged, often grounded over 'soft' relations $[15,16]$ and interactive governance between actors and instruments. This trend goes hand-in-hand with the emerging ideology of planning without a plan, which eventually points out a generative approach to urbanism [13]. The developing idea of urban complexity, therefore, shifted the mainstream interest in the literature $[6,17,18]$ from the plan (blueprint) to rules (design codes).

In this context, the increasing popularity of urban planning tools, such as codes, coding, or parametricism [19], can be considered as indicators of such a paradigmatic shift, suggesting the need for a new methodological basis for practicing urbanism [20]. Although the notion of rules and regulations is not new in urbanism, the innovative use of rules in the contemporary urban planning has been discussed little. Therefore, this study aims to present an insight into the application of smart design techniques in urban planning to initiate a shift from a pre-determined urban plan to rule-based design.

\section{Literature Review}

A rule-based system is a particular type of expert system, which typically consists of a set of if-then rules. Such rules can be used in the real world for both academic and practical purposes. In general, rule-based systems are involved in knowledge discovery tasks for both purposes and predictive modeling tasks for the latter purpose [21].

To date, several contemporary movements have explored the use and utility of design codes in different ways, proposing practical methods that can frame urban composition into a series of small algorithms [22]. Alexander [23], for instance, in the foreword of his notes on the Synthesis of Form, proposes an approach based on the idea that the physical complexity of a city could be resolved into a small system of interacting and conflicting independent patterns. Under the term generative planning and design, Alexander et al. [24] proposed a precise definition of generating systems, "whose parts and rules will (incrementally) create the necessary holistic system properties of their own accord." Similarly, Rowe and Koetter [25], with their polemical article Collage City, claimed a pluralist approach for the multiplicity of fragmented urban fabrics as the assemblage and fusion of different styles and programs, connoting in this way the notion of design for (urban) complexity. Forrester [26] identified and described the systemic structure responsible for the dynamics of urban development and decay through repeated computer simulations of the changing ratios of critical urban development factors, such as population, housing, and industry. More recently, the Sorkin's Local Code [27] and the Lehnerer's Grand Urban Rules [6] advance a methodology to enrich the morphological quality of cities through the design of specific rules.

According to Lynch [28], "some refer to form, some to the process of creating it, some to its subsequent performance. Some are legal minimums, others are desirable optimums used as guides in design, some refer to established ways of doing things, some are predictions, and others are arbitrary standardizations that limit unwanted variations in the form". Punter [29] placed design codes in relation to other urban planning and design documents in a spectrum from comprehensive/city-wide to site-specific/topic-specific scope, as follows: City-wide design strategies; Public realm strategies; City center design strategies; Quarter plans; Neighbourhood regeneration strategies; Master plans; Design codes; Streetscape manuals; Signage manuals, lighting/banner strategies; Design briefs. Christiaanse [30] instead provided a more synthetic distinction of urban design rules into three categories. The first category consists of dry, administrative rules able to regulate rights and plights from a juridical perspective; the second category consists of rules formulated from a more subjective and design vision; the third category comprises strategic steering instruments that focus on the control of dynamic variables. 
Considering the discussed classifications, 'rule-based design' could be achieved by stressing the border between two different ruling processes: the first involves codes used as 'juridical instruments' and those used as 'design tools.' This differentiation is not associated with the code on itself, but with the scope and the process of codification. A famous example of expressing this passage lies in the difference between 1916 and 1961 New York Zoning Regulation Laws (Figure 1). The 1916 Law divided Manhattan into three districts according to a Set Back Street Ratio rule. Depending on location, the buildings were permitted to rise from the street edge either once, one and a half or twice the width of the street. As later visualized by Hugh Ferriss in his Metropolis of Tomorrow [31], this rule produced the canyon-like effect typical of Manhattan without formally defining maximum building heights or widths. In this sense, the rule codification was driven by the mere need to avoid those individual buildings that could cast shadows onto their neighborhoods. This stance became a rule that was visualized by the Ferriss' envelops and applied by private developers. The 1961 Law did the exact opposite; instead, it started from the analysis of the qualities of existing buildings and modeled upon them a set of regulations. Using as prototypes Mies van der Rohe's Seagram Building (1958) and the Leven House by Skidmore, Owings, and Merrill (1952), the 1961 Law defined a series of rules such as plaza bonus, floor area ratio, sky exposure plane, allowing great flexibility while consistently endowing structures with slender profiles. If the first process embeds a more deductive nature-starting from a general statement, then applied and tested in several cases-the second follows an inductive path that starts from the specific quality of some precise case studies that are generalized into a broad ruling system. Similarly to what has been proposed in simulation [32,33] and visioning methods [16], in the first case, the technique is based on an abstract rationality with respect to reality, building models for the simulation of reality to understand in advance the unfolding of the facts of what will happen; in the second, instead, it investigates, after the event, the most hidden modalities according to which a specific event happened and established the basic rules for its reproduction [34].
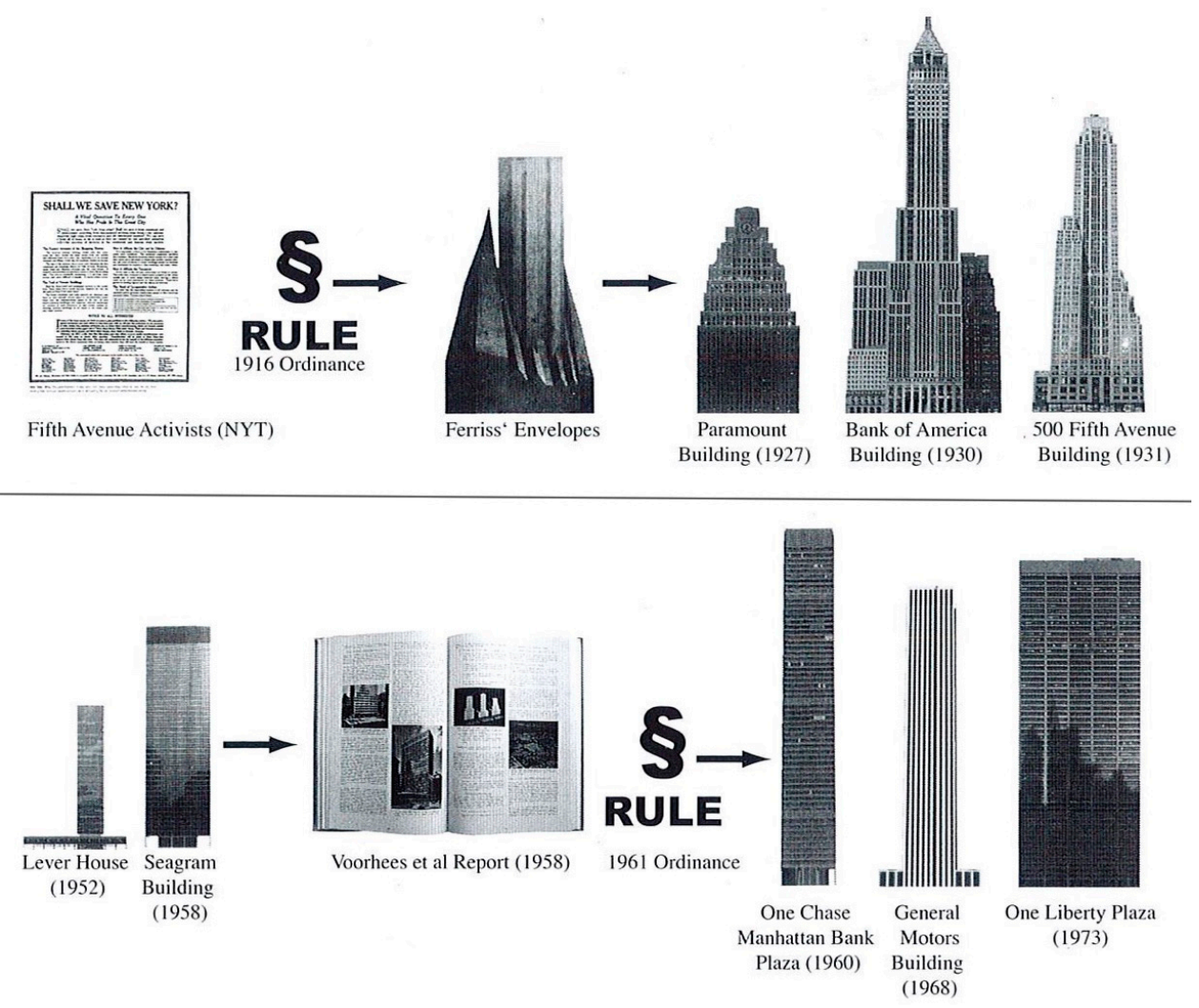

Figure 1. Different codification processes between the 1916 and 1961 Zoning Resolution in New York City. Derived from [29]. 
This distinction allows framing the core of this contribution defining the working framework of the rule-based design. If the first approach is, in fact, mainly juridical-recalling the various forms of building codes meant to govern at various scales spatial parameters such as urban density, distances, height, or materials - the second comes instead from a more exact and precise design process and selection. From an operational perspective, the first group collects more institutional coding experiences, such as the already mentioned building codes or hygienic-sanitary regulations, meant to govern at various scales spatial parameters, such as urban density, distances, height, and materials, but also the growing number of guidelines, compendiums, and manuals provided by national and international organizations and institutions [35-37]. Such rules are often generic stances applied to norm a vast plea of condition and contexts, forming altogether a possible catalog from which a design process could still be inspired and informed. The second group is instead composed of more coherent and site-specific design operations, which, at least theoretically, are meant to open up spaces of possibilities to create freedom in the design realm through preserving specific qualities. As clarified through the different New York Zoning Law, the second group is populated by case studies in which the coding activity is the final step of the design process, in which a coherent grammar is built out of a vocabulary made of single rules.

In light of these considerations, the intention of this contribution is not to investigate the vast plea of codes, design guidelines, and policies that allow controlling the evolution of the urban form and consistency from a juridical point of view, neither to select, among them, the best-performing ones. The main interest, instead, turns around the definition of a more comprehensive working method and the outline of a research field grounded over the use of the rules as design tools, which could help to frame the rule-based design approach.

\section{Materials and Methods}

This study adopts a qualitative comparison method to formulate a possible practical framework for sustainable urban planning through the smart technique of rule-based design. For this purpose, in the second chapter, different coding approaches in urban planning, both as juridical instruments and design tools, are explained during the last century. In the following, by discussing three contemporary cases, we explore practices of rule-based design in urban planning, to elaborate on the definition of the rule-based design framework. Finally, we highlight a series of primary factors and criteria of the coding approach that appear to be relevant to inform the actual design processes in the context of complexity and suggest a relevant base for the possible integration of the rule-based generative methods into urban planning and design.

\section{Results}

According to the literature analyses, rules and codes emerged as helpful instruments and have been pursued many times in the history of urbanism. Urban planning is a sophisticated task with many decision-makers, stakeholders, and participants, involving many agreements $[38,39]$ that can be formally represented by sets of codes that together could constitute a grammar [40]. Although the term code might be applied loosely in practice to mean any form of design guidance, in principle, it is possible to attempt some more specific definitions. Moreover, the literature suggests a clear distinction between two ruling processes: codes used as 'juridical instruments' and those used as 'design tools'. On the base of this distinction, the rule-based design approach has been framed, meaning with it an operational [30] and generative [24] methodology in planning and urban design, in which an integrated set of rules, selected through a design operation [6], is intended to be able to steer and control the forces that guide urban transformations by, at the same time, allowing freedom and preserving specific qualities [7].

The last decades have seen a considerable increase in the number of applications of the rule-based design approach. Although they significantly differ in terms of scales of interventions, genesis, motivation that fostered them, or the freedom they guarantee (Figure 2), the majority of these examples 
belong to the planning instruments of binding land-use plans. These instruments are consistent with the different national planning systems, but in general, they are intended as the chief instrument for implementing local government planning and constitutes the basis for other measures needed to be implemented. They contain legally binding specifications steering and controlling urban development structures, the use of land for building and other purposes.

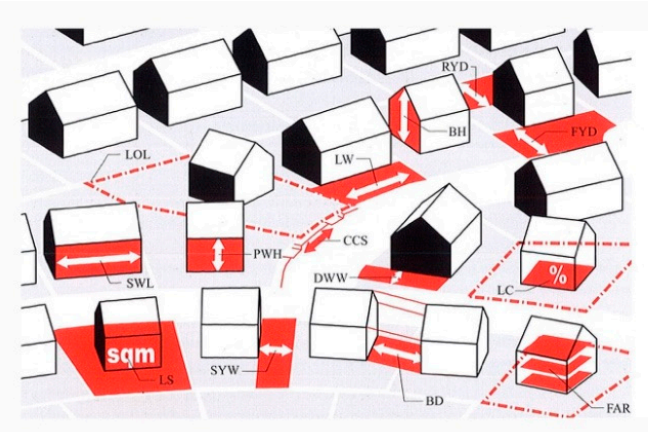

(a)

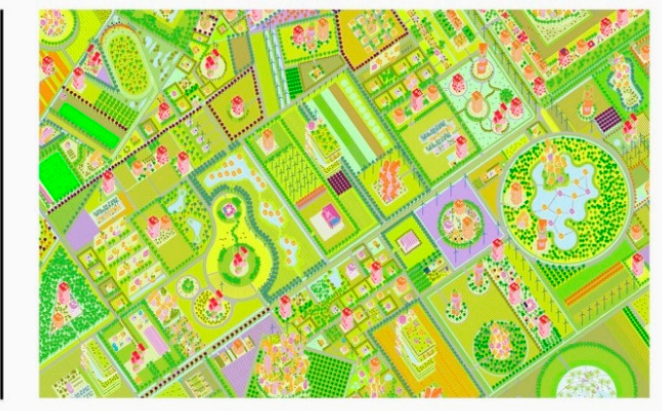

(b)

Figure 2. Two extreme examples of rule-based design between over-prescription and laissez-faire. (a) Zoning Handbook of the New York City Department of City Planning (2006), where approximately a dozen formal rules determine the official form and design of New York residential buildings: BD building distance (min), CCS curb cut spacing ( $\mathrm{min}$ ), DWW driveway width (min), FAR floor area ratio (max), FYD front yard depth, LC lot coverage (max), LW lot width (min), PWH perimeter wall height (max), RYD rear yard depth, SYW side yard width, SWL street wall length (max) [6]. (b) Freeland development strategy from the Dutch group MVRDV in which an area of $4300 \mathrm{sqm}$ is developed without a masterplan but using only a series of simple parameters related to land use percentages: $18 \%$ construction, $8 \%$ roads, $13 \%$ public green, $2 \%$ water, and $59 \%$ urban agriculture [41].

\subsection{Wijnhaven Island Masterplan and Other KCAP Projects}

The Wijnhaven Island masterplan, developed in 1996 by the Dutch group KCAP architects, represents a clear example of the rule-based design approach [6,42]. Wijnhaven Island is located between the center of Rotterdam and the River Maas and was initially composed of a block development of up to seven stories standing on the terrain surrounded by water. The idea of the Department of Urban Development and Public Housing of the city of Rotterdam was to densify the island through high residential towers on top of the mainly unsalable offices located in the original structures. To this end, the Urban Development Plan allowed that, depending on the plot size, 22 cubic meter increments could be added per each meter of the land surface. For this project, no plan has ever been drawn up. The KCAP office defined the relevant qualities on the basis of the few rules contained in the applicable regulations: no tower may overshadow another, nor a neighboring building, in an excessive way; each tower was required to provide views onto the nearby River Maas through a minimum number of windows; the towers had to be provided with street addresses, and their forms should manifest a certain slenderness (Figure 3a). The absence of a clear plan and the lack of a division into stages has brought about a situation in which the first developer to erect a tower on the terrain would automatically enjoy the most considerable degree of design freedom. The first to build had the greatest choice of sites and did not need to orient himself to existing towers [42]. Standing there today on the terrain, close to one another, are five slender towers. An uncommon situation for a European city, and perhaps possible, according to the author, only for the renunciation from the very beginning of any precise, plan-like representation of the ultimate result [6]. 


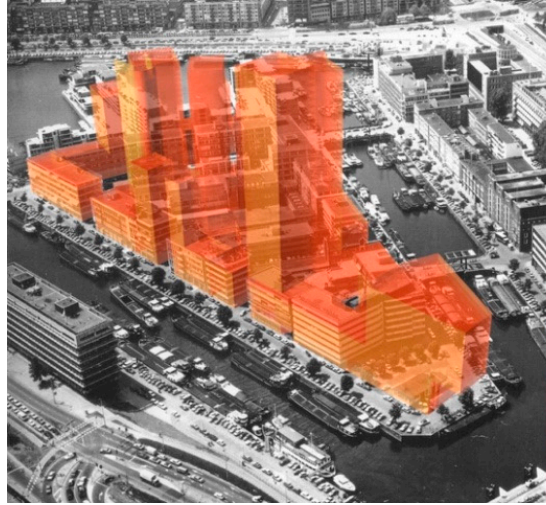

(a)

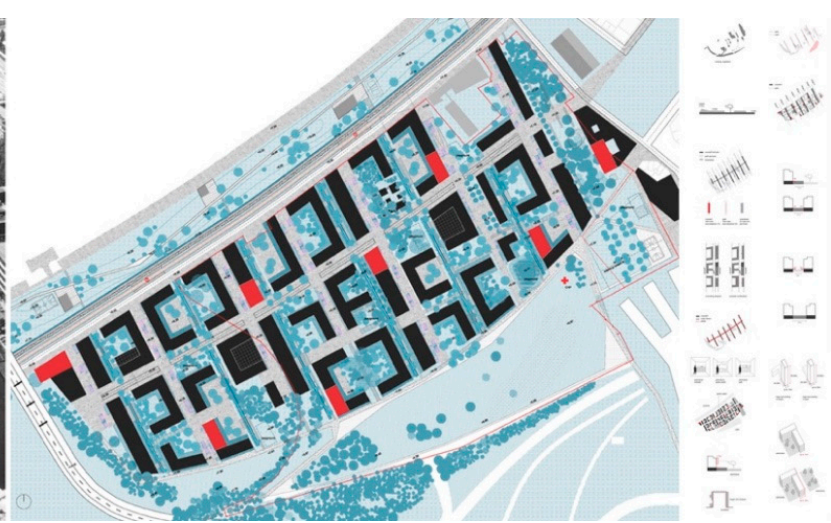

(b)

Figure 3. (a) Wijnhaveneiland project in Rotterdam from KCAP architects and planners (1996), simulation of the possible distribution of towers [42]; (b) Nieuwe Zuid masterplan in Antwerp from Studio Associato Bernardo Secchi Paola Viganò, Milan, Italy (2011), the final version of the masterplan and selection of the implementation rules [43].

Many other examples from the KCAP office could be listed, proposing similar projects which are not drawn, but simulated, visualized, and finally programmed through the definition of multiple variants. Such an approach could be recognized in the software developed for the city of Kaisersot, in the design for the Grossmünster area in Zurich or the Goodsyard Bishopsgate in London, and the grand masterplan for Hafencity in Hamburg.

\subsection{Nieuwe Zuid Masterplan from Studio Associato Bernardo Secchi Paola Viganò}

Recently, many binding land-use plans have been grounded on the combination of a robust spatial framework, meant to foster connectivity and livability of public spaces, with a system of flexible rules, dedicated to governing long-term developments and promote specific urban and building qualities. The Nieuwe Zuid master plan shows this combination. The project is the result of a design competition won in 2011 by the Studio Associato Secchi Viganò for the transformation of a vast area at the southern edge of the city center of Antwerp into a new mixed and dense urban environment. The implementation process that followed the design competition-which involved the City of Antwerp, the Studio Associato Secchi Viganò, and the promoter Triple Living group-was meant to secure the qualities of the master plan and keep, at the same time, development flexibility. As mentioned by the authors, "the project for a new part of the city is always a complex and layered operation. It deals with the force of settling new rules on top of an already urbanized area; with the re-interpretation of an existing context through the gaze of a new functional program; with the time variable that needs flexibility, inside a clear spatial structure; with the coexistence of a plurality of projects and actors that will animate the new urban space, without producing a banalized catalog of spaces and buildings." The final result of the work can be synthesized into a clear fixed spatial structure and a set of rules that vary from functional zoning, floor space, regulations of phasing, the position of paths, streets, and water infiltration systems, building measurements, and shading. Beyond these spatial rules, the master plan proposed some more original systems to foster organizational qualities, such as the necessity for each dwelling to have a panoramic view towards a green space, the pre-greening strategy and the mandatory separation between the underground parking and the dwelling staircases, meant to activate and secure the public spaces and encourage public transport usage (Figure 3b).

The full realization of the project will take at least 15 years, but today, a diversified plea of buildings is already standing on a coherent system of public spaces detailed by the landscape architect Bureau Bas Smets and the design competition and the building permits for many buildings have been already delivered. With around 2000 new homes, new facilities and a large park, Nieuwe Zuid is considered by the City of Antwerp a successfully sustainable neighborhood in which both the master 
plan as well the implementation process - based mainly on the definition of a system criteria and parameters-have been able to define an effective interactive tool between private stakeholders, civil servants, and future inhabitants.

\subsection{Wienerstrasse Masterplan from Spaziozero Atelier}

The Wienerstrasse masterplan in Linz from Spaziozero Atelier portrays a similar example. The project is the winning entry of the European 14 competition (2016). The proposal aimed to connect the inner city of Linz with the southern districts through a new neighborhood of 110,000 sqm located just behind the Linz central train station. As in the case of Antwerp, a spatial structure has been defined; in this case, through the use of the metaphor of the tartan, intended as a pattern consisting of crisscrossing horizontal and vertical bands, each one representing a different mode of transportation and a different type of space and activities. Along with the streets and a series of small squares and pocket areas, the tartan metaphor embeds in a coherent spatial structure also three large public spaces: a new square along the main axis of Wienerstrasse, a linear park along the railway and another park at the center of the development. Although the implementation phase is not yet concluded, the design team has already drafted in the competition phase a series of rules meant to govern the development, which range from floor space indexes, land coverage ratios, rules of phasing, shadow casting, but also particular prescription for the neighborhood main entrances and for the relationships between ground floors and public spaces.

Therefore, similarly to the processes proposed by the New York Zoning Law of 1961, the Wienerstrasse project tested in a detailed masterplan the optimal future configuration of the district, clarifying design decisions and qualitative principles (Figure 4). During the implementation phase, the masterplan layout was then translated into synthetic binding fix spatial systems composed of public spaces, streets, preserved heritage, parks, and plots. Together with this fixed structure, the ruling system was introduced, which was meant to both articulate and detail the public environments, as well as define limits and prescriptions to the private developments of the single plots, which will be designed by different architects.
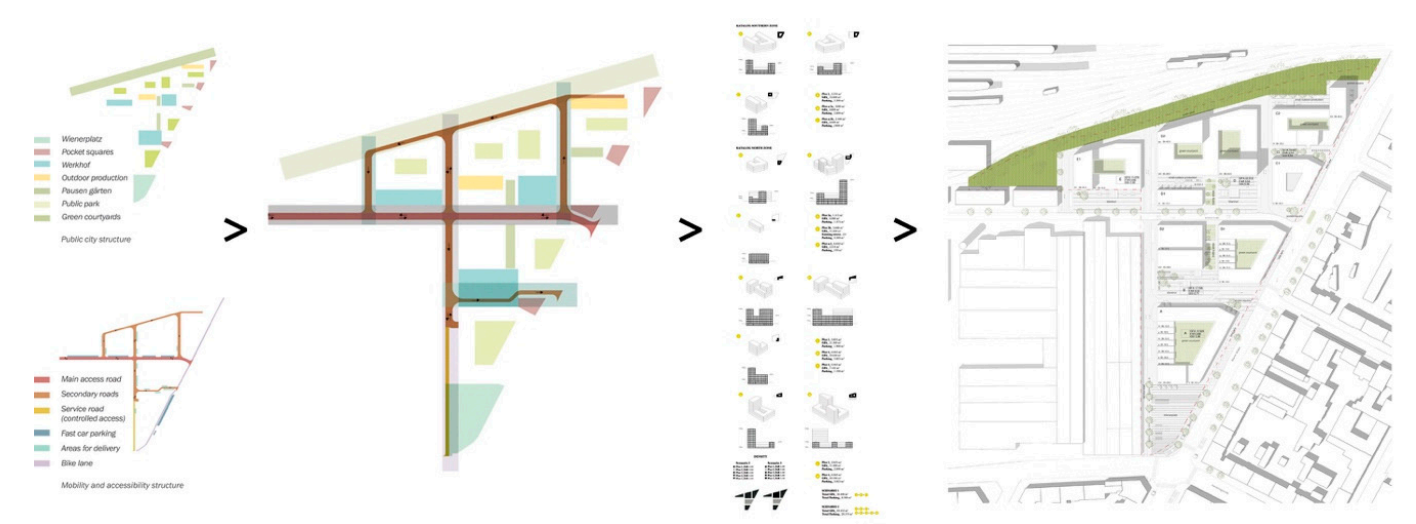

Figure 4. Wienerstrasse district in Linz from Spaziozero atelier (2017), the process of implementation; on the left: binding fix system of public spaces; in the middle: set of urban rules; on the right: flexible configuration of the plan. Source: Spaziozero atelier, 2017.

\section{Discussion}

In the last decades, the ideology of managing the city form and performance through pre-determined plans has gradually lost its validity. Consequently, planners must have the right toolset for both future plan changes and assess existing conditions [44]. The objective of this contribution is to respond to this disciplinary weakness. Indeed, the case studies provided in the previous section highlight a series of main factors of the coding approach that appear to be relevant to inform the actual 
design processes in the context of complexity, suggesting a relevant base for the possible integration of the rule-based generative methods into urban planning and design.

The first factor, also mentioned in Carmona et al. [7], is the capacity to deliver speed and quality in the design process, offering variety with harmony. Although this factor is not necessarily an inevitable product of the use of codes, nor are codes the only way of achieving it, the definition of rules helps improving flexibility and freedom between the different phases of the design process. As clearly expressed in the Wijnhaven Island master plan, the definition of a flexible ruling system leaves open a vast amount of compatible design solutions through which the final result was not predictable in advance.

Analysis of the case studies reveals how the definition of rules in the design process help to reduce the number of negotiations and planning inquiries. The second factor of the rule-based design approach is, therefore, the capacity to reduce the length of the procurement period, by leaving, at the same time, the space for new and innovative solutions. As mentioned by the authors of the Nieuwe Zuid and Wijnhaven Island master plans, the proposal of a flexible set of rules could support the implementation process, fostering an effective interactive tool between private stakeholders, civil servants, and future inhabitants.

The third factor is the distinction between the 'code writer' and the 'building designer' [7]. Although this separation seems an innate character of the urban design discipline, Christiaanse [30] recalls how remarkably "there are still people who think that one could create a functioning piece of the city using a fixed, beaux-arts urban design." Against this perspective, the three case studies limit the design operation to the organization of the main public structures, maintaining, as stated by Christiaanse "a certain modesty towards architecture, which may flourish in a thousand flowers; in other words, urban design is about creating conditions for freedom." [30]. This distinction, already stressed by Ryan [45], was described by Marshall [17] through a useful analogy that highlights the role of the code writer in street design. He points out that "the street code-writer is like an editor of a book, and the building and road designers correspond to the individual authors. The point here is that we can obtain a street (book) without necessarily having a single street designer".

The fourth factor consists of the capacity to propose an inclusive design process able to clarify the specific qualities that have to be delivered. This could help to frame, during the design process, the level of urban qualities that have to be achieved in a project, plan or policy, so as to give the operational tool to measure and evaluate it [46].

If those four factors could help to frame a coherent system to evaluate rule-based design projects, two criteria could be highlighted that help a distinction between the three analyzed case studies.

The first criterion is related to the presence or not of a clear fixed structure in which the ruling system operates. If in the Nieuwe Zuid and Wienerstrasse master plan, synthetic binding fix spatial systems are defined, which guarantees an optimal definition of the public spaces, the Wijnhaven Island master plan instead is solely defined according to rules, achieving, in this way, a maximum level of design flexibility.

The second criterion is related to the nature of the proposed rules and their capacity to perform an impact not only on the spatial urban composition but also on organizational aspects. In particular, the Nieuwe Zuid masterplan, by proposing, for instance, rules related to the pre-greening strategy or the mandatory separation between the underground parking and the dwelling staircases, introduced at the master plan phase some organizational requirements meant to frame not only the architectural design but also the overall process of realization of the neighborhood and the way in which future dwellers will live in it. This aspect was limited in the Wijnhaven Island master plan to the need for the new towers to provide with street addresses, remaining instead ignored in the Wienerstrasse master plan.

\section{Conclusions}

A rule-based system is a particular type of expert system, which is made up of a set of rules, which typically takes the form of if-then rules. In general, such rules can be designed through the use 
of expert knowledge or through learning from real data. Based on this viewpoint, rule-based systems can be designed in two ways: expert-based design and data-based design.

Under the terms of codes, coding or parametricism, generative planning and design, planning without a plan, a smart theoretical and operational design technique is emerging, which could help to formulate a design working framework alternative to blueprint planning. This contribution aimed to frame a precise approach, that can be referred to as 'rule-based design', meaning with it an operational and generative methodology in urban planning and design, in which an integrated set of rules, selected through a design operation, is intended to be able to steer and control the forces that guide urban transformations by, at the same time, allowing freedom and preserving specific qualities.

By investigating three case studies, this contribution appointed to the rule-based design approach some specific factors: (i) the potential to deliver speed and quality in the design process, offering variety with harmony; (ii) the capacity to reduce the length of the procurement period, by leaving, at the same time, the space for new and innovative solutions; (iii) the distinction between the 'code writer' and the 'building designer'; (iv) the capacity to clarify the specific urban qualities that have to be achieved in a project, plan or policy, so as giving the operational tool to measure and evaluate it.

This branch of discussion suggests, therefore, the possible integration of the rule-based generative methods into urban planning and design processes, working both as guidelines for the design process as well as criteria for evaluating its result.

At the same time, two criteria have been introduced to clarify different characteristics of the three case studies: (i) the presence or not of a clear fixed structure in which the ruling system operates; (ii) the capacity of the ruling system to perform an impact not only on the spatial urban composition but also on organizational aspects.

What emerges from the analysis of the case studies is that a combination between fixed spatial principles-which defines the infrastructure of mobility and public spaces—and a more open and operationally manageable system of spatial and organizational rules, helps to face long term and vast scale development, while granting a coherent, though heterogeneous and deferred, transformation.

Nevertheless, despite the existing rich theoretical perspective, the operational insight of the rule-based design is yet to be developed as well as its capacity to address context different from the north European and American and planning instruments different from the binding land-use plans.

Author Contributions: Conceptualization, C.P. and G.D.L.; data curation, C.P. and A.S.D.; methodology, C.P. and A.S.D.; supervision G.D.L.; writing—original draft, C.P.; writing-review and editing, C.P., G.D.L. and A.S.D. All authors have read and agreed to the published version of the manuscript.

Funding: This research received no external funding.

Conflicts of Interest: The authors declare no conflict of interest.

\section{References}

1. Prigogine, I. Order out of Chaos; Flamingo: London, UK, 1985; ISBN 978-0-00-654115-8.

2. Stengers, I.; Lissack, M. The Challenge of Complexity. Emerg. Complex. Organ. 2004, 1.

3. Johnson, S. Emergence. The connected Lives of Ants, Brains, Cities and Software; Scribner: New York, NY, USA, 2001.

4. Portugali, J. Complexity Theories of Cities Have Come of Age: An Overview with Implications to Urban Planning and Design; Springer Science \& Business Media: Berlin, Germany, 2011; ISBN 978-3-642-24544-2.

5. Batty, M. Cities and Complexity: Understanding Cities with Cellular Automata, Agent-Based Models, and Fractals; MIT Press: Cambridge, MA, USA, 2007; ISBN 978-0-262-52479-7.

6. Lehnerer, A. Grand Urban Rules, 1st ed.; Nai Uitgevers Pub: Rotterdam, The Netherlands, 2009; ISBN 978-94-6208-054-6.

7. Carmona, M.; Marshall, S.; Stevens, Q. Design codes: Their use and potential. Prog. Plan. 2006, 65, $209-289$. [CrossRef]

8. Ben-joseph, E. The Code of the City: Standards and the Hidden Language of Place Making; MIT Press: Cambridge, MA, USA, 2005; ISBN 978-0-262-52445-2. 
9. Gardiner, J. The Codemaker. Hous. Today 2004, 23, 26-28.

10. Southworth, M. New Urbanism and the American Metropolis. Built Environ. 2003, 29, 210-226. [CrossRef]

11. Donald, A. Coding is aid to faster and better urban design. Update Deliv. Sustain. Communities 2003, 2, 4.

12. Vitruvius: "Ten Books on Architecture"; Rowland, I.D.; Howe, T.N. (Eds.) Cambridge University Press: Cambridge, UK, 1999.

13. Çalışkan, O. Parametric Design in Urbanism: A Critical Reflection. Plan. Pract. Res. 2017, 32, 417-443. [CrossRef]

14. Batty, M.; Longley, P. Fractal Cities: A Geometry of Form and Function; Academic Pr: London, UK, 1994; ISBN 978-0-12-455570-9.

15. Cavaco, C.; Costa, J.P. Administrative Organisation and Spatial Planning in Portugal: A Push towards Soft Planning Spaces in Europe? In Shaping Regional Futures: Designing and Visioning in Governance Rescaling; Lingua, V., Balz, V., Eds.; Springer International Publishing: Cham, Switzerland, 2020; pp. 87-101, ISBN 978-3-030-23573-4.

16. Pisano, C.; Saddi, V. Open and Closed Figures in Dutch Spatial Planning. In Shaping Regional Futures: Designing and Visioning in Governance Rescaling; Lingua, V., Balz, V., Eds.; Springer International Publishing: Cham, Switzerland, 2020; pp. 173-181, ISBN 978-3-030-23573-4.

17. Marshall, S. Urban Coding and Planning; Routledge: New York, NY, USA, 2011; ISBN 978-1-135-68927-8.

18. Talen, E. City Rules: How Regulations Affect Urban Form, 2nd ed.; Island Pr: Washington, DC, USA, 2012; ISBN 978-1-59726-692-5.

19. Frazer, J. An Evolutionary Architecture; Architectural Association Publications: London, UK, 1995.

20. Verebes, T. Masterplanning the Adaptive City: Computational Urbanism in the Twenty-First Century, 1st ed.; Routledge: London, UK; New York, NY, USA, 2014; ISBN 978-0-415-53479-6.

21. Liu, H.; Gegov, A.; Cocea, M. Rule-based systems: A granular computing perspective. Granul. Comput. 2016, 1, 259-274. [CrossRef]

22. Pisano, C. Patchwork Metropolis. Progetto di Città Contemporanea; Research; LetteraVentidue: Siracusa, Italy, 2018.

23. Alexander, C.W. Notes on the Synthesis of Form; Underlining; Harvard Univ Pr: Cambridge, MA, USA, 1972; ISBN 978-0-674-62751-2.

24. Alexander, C.; Neis, H.; Anninou, A.; King, I. A New Theory of Urban Design; OUP: New York, NY, USA, 1987; ISBN 978-0-19-503753-1.

25. Rowe, C.; Koetter, F. Collage City; Reprint; Mit Pr: Cambridge, MA, USA, 1978; ISBN 978-0-262-68042-4.

26. Forrester, J. Urban Dynamics; M.I.T. Press: Cambridge, MA, USA, 1969.

27. Sorkin, M. Local Code: The Constitution of a City at 420N Latitude; Princeton Architectural Press: New York, NY, USA, 1993; ISBN 978-1-878271-79-2.

28. Lynch, K. Site Planning; M.I.T. Press: Cambridge, MA, USA, 1971.

29. Punter, J. Urban Design Strategies in Britain-The Key Questions. Built Environ. 1999, 25, 371-385.

30. Christiaanse, K. Remote control. In Grand Urban Rules; Nai Uitgevers Pub: Rotterdam, The Netherlands, 2009; ISBN 978-94-6208-054-6.

31. Ferriss, H. The Metropolis of Tomorrow; Ives Washburn: New York, NY, USA, 1929; ISBN 978-0-486-43727-9.

32. Cecchini, A.; Indovina, F. Strategie per un Futuro Possibile; Franco Angeli: Milano, Italy, 1992; ISBN 978-88-204-7586-4.

33. Bozzuto, P.; Costa, A.; Fabian, L.; Pellegrini, P. Storie del Futuro; Edizioni Officina: Roma, Italy, 2008.

34. Cecchini, A.; Indovina, F. Simulazione. Per Capire e Intervenire Nella Complessità del Mondo Contemporaneo; Franco Angeli: Milano, Italy, 1989.

35. UN-Habitat. A New Strategy of Sustainable Neighbourhood Planning: Five Principles—Urban Planning Discussion Note 3-UN-Habitat. Available online: https://unhabitat.org/a-new-strategy-of-sustainableneighbourhood-planning-five-principles (accessed on 21 December 2019).

36. NACTO. Urban Street Design Guide. Available online: https://nacto.org/publication/urban-street-designguide (accessed on 21 December 2019).

37. English Partnership; The Housing Comporation. Urban Design-Compendium Manual; Llewelyn-Davies: London, UK, 2000.

38. Shirvani-Dastgerdi, A.; De-Luca, G. Boosting city image for creation of a certain city brand. Geogr. Pannonica 2019, 23, 23-31. [CrossRef] 
39. Shirvani Dastgerdi, A.; De Luca, G. Strengthening the city's reputation in the age of cities: An insight in the city branding theory. City Territ. Arch. 2019, 6, 2. [CrossRef]

40. Beirão, J.; Duarte, J.; Stouffs, R.; Bekkering, H. Designing with Urban Induction Patterns: A Methodological Approach. Environ. Plan. B Plan. Des. 2012, 39, 665-682.

41. Maas, W. Oosterwold Freeland, Almere. In Designing Change; Firley, E., Ed.; nai 010 Publisher: Rotterdam, The Netherlands, 2019; pp. 234-243.

42. Groenendijk, P. The Red Apple and the Wijnhaven Island; 010 Uitgeverij: Rotterdam, The Netherlands, 2009; ISBN 978-90-6450-700-7.

43. RUP NIEUW ZUID. Available online: https://www.antwerpen.be/docs/Stad/Stadsvernieuwing/ Bestemmingsplannen/RUP_11002_214_10014_00001/RUP_11002_214_10014_00001_0001Deel_tn.html (accessed on 8 November 2019).

44. Agius, T.; Sabri, S.; Kalantari, M. Three-Dimensional Rule-Based City Modelling to Support Urban Redevelopment Process. Int. J. Geo-Inf. 2018, 7, 413. [CrossRef]

45. Ryan, B.D. The Largest Art: A Measured Manifesto for a Plural Urbanism; Mit Pr: Cambridge, MA, USA; London, UK, 2017; ISBN 978-0-262-03667-2.

46. Blečić, I.; Cecchini, A.; Talu, V. The Capability Approach in Urban Quality of Life and Urban Policies: Towards a Conceptual Framework. In City Project and Public Space; Serreli, S., Ed.; Urban and Landscape Perspectives; Springer: Dordrecht, The Netherlands, 2013; pp. 269-288, ISBN 978-94-007-6037-0.

(C) 2019 by the authors. Licensee MDPI, Basel, Switzerland. This article is an open access article distributed under the terms and conditions of the Creative Commons Attribution (CC BY) license (http://creativecommons.org/licenses/by/4.0/). 